\title{
Understanding the Black Box of Communication in a Common-Pool Resource Field
}

\section{Experiment}

\section{Maria Claudia Lopez ${ }^{\mathrm{a}, \mathrm{c}}$}

\section{Sergio Villamayor-Tomas ${ }^{b, c}$}

a Corresponding author. Department of Community Sustainability, Michigan State University 326 Natural Resources Building, 480 Wilson Road. Michigan State University. East Lansing, MI 48824.

e-mail:mlopez@msu.edu

b ICTA, Autonomous University of Barcelona

c The Vincent and Elinor Ostrom Workshop in Political Theory and Policy Analysis, Indiana University

Acknowledgments: Previous versions of this paper were presented at The Vincent and Elinor Ostrom Workshop in Political Theory and Policy Analysis, Indiana University, and at the conference "Lab and Field Experiments on Social and Commons Dilemmas", held at Arizona State University in 2009. We express our gratitude to Juan Camilo Cardenas who shared with us not only his database but also provided valuable comments to early version of this paper. This manuscript was enhanced by the extended and valuable comments from Elinor Ostrom and Charles Pavitt. We are also grateful to Paula Andrea Zuluaga for her assistance at different stages of this research. 


\begin{abstract}
It is well proven that communication enhances cooperation in public goods and commonpool resource experiments. It is less well understood why and how communication affects cooperative behavior and whether that impact is mediated by the sharing of a common context and the individuals' every day experiences. This paper aims to close this gap by means of a systematic content analysis of communication transcripts from field experiments. The paper analyzes communication statements shared by participants in a series of common-pool resource experiments conducted in rural Colombia. We first classified each statement under two categories: topic and function. Then, we tested hypotheses about the impact of those statements on cooperation depending on (1) their reference to the "field context" and other topic categories; and (2) the "informational", "disapproval", or "group solidarity" function of the statements. According to our results, statements that contain references to the context affect cooperation depending on the function of those statements. When the statements fulfill an information role, the effect is negative, but when statements have the function of enhancing group solidarity, the effect is positive. The statements that have the strongest positive impact on cooperation are those fulfilling a disapproval function, particularly when the topic of the messages are the payoffs obtained by the group.
\end{abstract}

Key words: CPR experiments; field experiments; communication; content analysis; collective action 


\section{Introduction}

Social dilemmas are situations where individual selfishness is at odds with group interests. In the environmental field, social dilemmas have been traditionally associated to the extraction of common pool resources like water, forests and fisheries, and the provision of public goods such as infrastructure, soil conservation or water quality (Ostrom et al. 1994). Empirical studies have shown that local communities all over the world are able to communicate as a way of better managing shared resources and provide public goods without external enforcers (Agrawal 2014; Agrawal 2001; Andersson 2004; Baland and Platteau 1996; Ostrom 1990; Ostrom et al. 1992, 1994; Tucker 2010; Wade 1988). The role

of communication in non-cooperative social dilemma experiments has been tested in numerous laboratory experiments in a variety of disciplines (for meta-analyses see Balliet 2010 and Sally 1995; for an overview of initial findings see Ostrom et al. 1994). Communication has shown to increase cooperation in social dilemmas experiments as it increase the ability of individuals in a group to coordinate their actions to restrain their appropriation and maintain group extraction levels relatively low. This is not trivial, given the benefits that defect ( i.e., free ride on) offers (Ostrom 2006).

Despite the importance attributed to communication in social dilemma games, few studies have systematically analyzed the content of communication interactions (Bornstein 1992; Ostrom and Walker 1991; Ostrom et al. 1992; Pavitt 2011, Schwartz-Shea and Simmons 1991) and tested hypotheses about the role of communication in non-cooperative games (Orbell et al. 1988; Pavitt 2011; Pavitt et al. 2005; Simon and Gorgura 2003). A few studies have used content analysis systematically; however, none has done it with data from experiments done in the field with real users of natural resources. Some of the most cited hypotheses about why communication works refer to the provision and sharing of information, the role of social norms, and the emergence of group identity and solidarity (Bornstein 1992; Shankar and Pavitt 2002). Experimental studies have tested the validity 
of each of the hypotheses separately, with mixed results. Despite the efforts, there is still no evidence supporting either the dominance of one hypothesis over others, nor the compatibility between several of them (Cardenas and Ostrom 2004).

As in experiments in the laboratory, in field experiments there is evidence of the effectiveness of communication in promoting cooperation, but the levels of cooperation vary greatly across groups. Studies have shown how the effects of communication can vary depending on group dynamics and socioeconomic characteristics of participants (Cardenas 2003). Other studies have also demonstrated that when communication is allowed there is a positive impact on equity, measured with game earnings (Ghate et al. 2013). Overall, it is assumed that doing experiments in the field increases the external validity of the findings, because experiments are conducted with samples that are more representative of society and real-world context (List and Metcalfe 2014; Poteete et al. 2010). Scholars have shown that context is crucial to comprehend why institutions that manage natural resources may function in one scenario but fail in another one (Dietz and Henry 2008; Ostrom 2007; Ostrom et al. 2007; Poteete et al. 2010). In this paper we aim to explore the impact of context as embedded in the communication interactions within the field experiment as a mean to explain users' behavior during the experiment.

To our knowledge there are not studies investigating how the communication process of experiments conducted in the field are influenced by the participants' context. To fill this gap, we content-analyze communication transcripts from framed field experiments conducted in rural Colombia. The research questions are "To what extent are hypotheses explaining the role of communication in laboratory experiments applicable to the field? Are any of those hypotheses more robust than the others in the field setting? And, to what extent does the context permeate the communication interactions?"

The paper is organized as follows. In section 2, we present the theory and hypotheses driving the paper; section 3 addresses the methodology, including a description of the field experiments and an explanation of the content analysis and coding procedures; in section 
4, we present the results of the study; section 5 compromises the discussion of the results presented in section 4; and in section 6, we conclude and suggest areas for further research.

\section{Theory and Hypotheses}

Since the 1950s, more than 100 studies have found significant evidence to conclude that communication significantly increases cooperation in non-cooperative games. Two quantitative meta-analyses have synthesized the literature about the different conditions that mediate the impact of communication on cooperation in social dilemmas (Sally 1995 and Balliet 2010). Sally (1995) found that communication had an effect on cooperation after controlling for 23 different experimental conditions. According to the author, the frequency of discussion periods and the ability of participants to make promises significantly increased cooperation. In a similar meta-analysis, Balliet (2010) found that face-to-face discussion enhanced cooperation more than written messages. In addition, the author found that repeated communication during iterated dilemmas did not have a statistically larger impact than one-shot, pre-play communication.

Cardenas and Ostrom's (2004) “information layers" framework explains that in many social dilemma games, players search for information to create an internalized vision of the game, which may involve a set of payoffs that go beyond the formal/external game created and described by the experimenter. The internal-game values are then affected by three layers of information, to wit: the information players gather about the game conditions and dynamics ("material payoffs layer"), the information collected about other players' characteristics and the context in which the experiment is conducted ("group-context layer"), and their own values ("identity layer") (see Figure 1). Information and understanding about the material payoffs and dynamics of the game can emerge through trial and error, along a repeated interactions game, through verbal and visual communications, or through a combination of them. Similarly, understandings of other players' characteristics and sharing the context may also require some form of 
communication. Finally, mobilizing one's beliefs does not require communicating with anyone.

As illustrated in Figure 1 and further explained in the paragraphs that follow, the provision and information sharing, social norms, group identity and solidarity and the importance of the context hypotheses tested in this study can be framed within the "material payoffs" and "group-context” information layers of Cardenas and Ostrom's (2004) framework.

\begin{tabular}{|l|l|l|}
\hline Identity Layer & Group-context Layer & $\begin{array}{l}\text { Material payoffs Layer } \\
\text { Net payoffs from feasible } \\
\text { strategies, feasible strategies, } \\
\text { reputation and learning, } \\
\text { reciprocity... }\end{array}$ \\
$\begin{array}{l}\text { Wealth, } \\
\text { occupation, } \\
\text { experience, } \\
\text { values, } \\
\text { gender, } \\
\text { age, } \\
\text { education, } \\
\text { other-regarding preferences... } \\
\text { group identity, } \\
\text { cultural heterogeneity, } \\
\text { inequality, } \\
\text { cooperative/competitive setting... }\end{array}$ & \\
\cline { 1 - 1 }
\end{tabular}

Source: Cardenas and Ostrom 2004

\section{Figure 1: Information levels framework}

According to the group identity and solidarity hypothesis, communication contributes to the emergence and/or reinforcement of sympathy and shared interests among individuals in a group, which in turn facilitates cooperative behavior (Sally 2001). This hypothesis is based on our capacity to recognize, anticipate, and sympathize with each other's characteristics, feelings and thoughts, depending on how similar those characteristics are to ours. Such sympathy or social identity can increase with the proportion of shared attitudes and/or experiences and can modify our willingness to act strategically (Sally 2001). We depersonalize others and see them as typical members of a group (Turner et al. 1987). To the extent that others are categorized as members of our group, a motivational 
shift would occur, and group welfare would matter more than individual welfare (Bicchieri 2002).

Orbell et al.'s (1988) well-known findings about the within-group cooperation bias have been interpreted as evidence supporting the "group identity" hypothesis. Similarly, in a game where two groups were competing for the provision of a public good, Bornstein and Rapoport (1988) and Bornstein et al. (1989) found that within-group communication fostered more intragroup cooperation than between-group communication. Pavitt (2011) argues that group identity plays an important role in the first stages of the communicative act because it allows for a reason to cooperate in the first place, allowing the emergence of trust among decision makers. In the same line, Simon and Gorgura (2003) found that solidarity words within the group had a statistically positive effect on cooperation.

According to the above explanations, the group identity and solidarity explanation would be fulfilled though statements enhancing the feeling of belonging to a group among the individuals (Bornstein and Rapoport 1988; Bornstein et al. 1989; Orbell et al. 1988; Pavitt 2011; Sally 2001; Simon and Gorgura 2003). In this regard, our first hypothesis states the following:

H1: Statements that enhance group membership among the participants will result in lower group extraction levels.

According to provision and sharing of information hypothesis, communication can help participants understand the dynamics of the game as well as filling uncertainty gaps about the behavior of other players, which in turn increases cooperative behavior (Bornstein 1992).

Despite the intuitiveness of the hypothesis, empirical results are mixed. Kerr and KaufmanGilliland (1994) found that receiving comments from earlier game players or overhearing a discussion from an earlier game did not increase cooperation over a non-communication condition. Alternatively, Bochet and Putterman (2009) showed that allowing participants 
to make unidirectional and nonbinding pre-play announcements about their intended behavior has a strong effect on cooperation. Dawes et al. (1977) and Bouas and Komorita (1996) found that discussions about irrelevant topics do not facilitate cooperation as much as discussions about the social dilemma at hand. Chen and Komorita (1994) showed that while non-binding voluntary pledge messages did not improve cooperation over a noncommunication case, minimum agreements did improve cooperation, partially due to the extra information that the mechanism provided to the players about other players' pledges. In this regard, we propose our second hypothesis:

H2: Statements providing information about the social dilemma of the game or participants' behaviors will result in lower group extraction levels.

According to social norms hypothesis, communication can act as a form of sanctioning by bringing preexisting beliefs about what is socially appropriate in the game (Bicchieri 2002; Kerr and Kaufman-Gilliland 1994). Sanctions, whether occurring through fines or social shunning, counterbalance the individual benefits from uncooperative behavior and thus reduce the incentives to free ride (Gächter and Fehr 1999; Lopez et al. 2012; Masclet et al. 2003; Ostrom et al. 1994; Rege and Telle 2004). Sanctions require the existence of rules and/or norms that prescribe a particular course of action. One such social norm is the existence of a commitment norm according to which one should carry out those actions one has promised to perform, i.e. one's decisions and actions should be consistent (Kerr and Kaufman-Gilliland 1994). Another prevalent social norm in democratic societies is the golden rule or ethic of reciprocity that "one should treat others as one would like others to treat oneself" (Etzioni 1996). Kerr and Kaufman-Gilliland (1994) found that whenever communication triggered commitments to cooperate, the impact of such commitments on effective cooperation did not depend on the perceived self-efficacy of players, which pointed to the existence of social norms that played a role in addition to the payoffs of the game.

To the extent that much of the social control that accompanies social norms can be transmitted verbally through reproaching, our third hypothesis states the following: 
H3: Reproach statements about participants' behaviors will result in a decrease in group extraction levels.

One of the values of conducting framed field experiments is the fact that participants are more diverse than in laboratory experiments (Cardenas 2011; Henrich et al. 2010) and are confronted in the game with situations similar to those of their own context in their interactions with people and resources (Harrisson and List 2004; List and Metcalfe 2014; Poteete et al. 2010). A number of studies have used field experiments to explore the importance of context on cooperative behavior (see Torres-Guevara and Schlüter 2016 for a summary). Rustagi et al. (2010) measured conditional cooperation through experiments and compared it with results on forest conditions in 49 forest user groups in Ethiopia. The authors found that groups with more conditional cooperators had more productive forests, and these groups were also more likely to invest in forest patrols and thus to sanction free riders. Gelcich et al. (2013) conducted experiments with unionized and nonunionized fishermen in Chile. Their results show that unionized fishermen were more cooperative than the nonunionized ones. Among the unionized fishermen they found that fishermen from high-performance unions were more cooperative than fishermen from lowperformance unions. Other authors have found that there is no relation between people's context and their behaviors in the experiment. Hill and Gurven (2004) conducted social dilemma games with the Ache tribe in Paraguay, an indigenous community that traditionally shares food. Their results show that the cooperative behavior in their daily lives did not translate into cooperative behavior in the experiment. In another study done by Gurven and Winking (2008) with another indigenous group, the Tsiname tribe from Bolivia, found the same results.

Overall, the relationship between previous shared experiences and cooperation can be positive or negative depending on the cooperative experiences shared by the communities (Cardenas 2003; Cárdenas and Ostrom 2004; Ghate et al. 2013). It is less clear, however, whether the way such shared background is mobilized in communication interactions also affects cooperation. In this regard, our last hypothesis states the following: 
H4: Comments referring to the participants' context will affect group extraction levels.

\section{Methodology}

This study uses data obtained from a series of framed field experiments conducted with forest users in rural Colombia ${ }^{1}$ (Cardenas 2000, 2003). Eight participants were invited to participate in a common-pool resource game (CPR), recreating a situation in which a group of forest users must decide how much to extract from a shared forest (Cardenas 2000, 2003). The model used by Cardenas follows the one by Ostrom et al. (1994) capturing the increasing individual benefits from extracting the CPR, but decreasing costs caused by the negative externalities from the extraction of the other group members. The experiments were conducted in rural areas of Colombia with direct users of natural resources, extracting forest products such as firewood, timber, and hunting as main economic activities.

The experimental design included two sets of rounds. In the first set, participants faced 7 to 10 rounds of an "open access" regime, where participants were not allowed to communicate and no regulations were in place. During these rounds participants did not have any way to share information, to create agreements or to have non verbal communication since they were facing each others backs. In the second set of 7-10 rounds, participants were allowed to communicate with other group members for five minutes between rounds before making their decisions. During the communication process, participants were allowed to talk freely about any topic, but they were not allowed to change the rules of the game, threaten participants, or promise cash transfers after the game. The experiment was conducted with paper and pencil, and the communication process was tape-recorded and/or video-recorded with the authorization of participants.

\footnotetext{
${ }^{1}$ These experiments were conducted by Juan Camilo Cardenas. For more details on the experimental design and procedures, refer to Cardenas 2000. The first author transcribed all available information from the communication groups, and both authors did all the work related to the content analysis.
} 
There are very few studies that systematically analyze the content of communication interactions in non-cooperative game experiments (Orbell et al. 1988; Pavitt et al. 2005, 2006, 2007, 2009; Simon and Gorgura 2003). The work of Charles Pavitt and collaborators (2005) is, in our understanding, the most sophisticated work published in that direction so far. Following their work we split communication interactions into statements (see section 3.2) and classified each statement into two sets of categories. The first set sorts the statement according to topics, including discussions about the workings of the game, what occurred in past rounds, general strategies to be used in subsequent rounds, and more specific strategies to be used in subsequent rounds. The second set of categories looks at the function of the statements, including informing, proposing, computing, elaborating, evaluating, confirming, maintaining group cohesiveness ("positive maintenance"), reproaching ("negative maintenance"), and guiding the discussion ("procedural maintenance"). In the content analyses from a common-pool resource (CPR) experiment, Pavitt et al. (2005) found that strategy, maintenance, and procedure discussions were positively correlated with cooperation, whereas informational discussions had the opposite association. Similarly, Pavitt (2011) found that discussions of specific strategy, maintenance, and procedure were positively related to cooperation, while general strategy discussion, basic information exchange, and recapitulation of past experiences were negatively related to cooperation.

\subsection{The Field Experiments}

The experiments were conducted with a total of 120 individuals, half of whom were women. A total of 15 groups were included in the analysis of this study. Participants were seated in such a way that they were not able to see other participants' decision forms in order to keep their decisions private. Before the start of the experiment, instructions were read aloud by the monitor. During the rounds when communication was permitted, participants turned their chairs to face the other participants during the five minutes of the communication period. At the end of the stipulated time, participants were asked to return 
to their original positions to make their individual decisions, this process was repeated each time communication occurred.

Annex 1 includes the pay-off table containing the individual net gains during the experiment. Each participant individually and anonymously had to choose the number of months - "My months in the forest" - she/he wanted to spend extracting forest resources (columns 0-8). After the eight participants made and wrote their simultaneous extraction decisions, a monitor collected all the decision cards and added the individual decisions to announce in public the total amount of months the group spent in the forest (individual extractions were not announced). With that information, each participant was able to calculate "Their months in the forest" (the difference between what was announced by the monitor and "My months in the forest"); then, with that number (rows 0-56), each participant also was able to calculate his/her own earnings in that round. The economic model behind the pay-off table stands that the group optimum is reached when each individual spends one month extracting resources from the forest. On the other hand, the Nash equilibrium is achieved if every individual spends six months collecting resources

from the forest. Cooperation in the experiment implies extracting units close to the group optimum, whereas free riding is achieved by extracting units close to the Nash equilibrium.

\subsection{Content Analysis}

In this section, we present a description of the transcription, unitizing, and coding steps involved in the systematic content analysis of communication interactions.

\subsubsection{Transcript preparation and unitizing}

The familiarity of one of us with the language and idioms used by participants was crucial at the transcription stage, as many of the expressions recorded were very specific to the field context. Additionally, the transcripts were checked for accuracy with members of the field team that had conducted the experiments whenever necessary. Although it was possible to assign statements to different speakers, it was not possible to identify the 
speaker's identity, attributes or player number, neither to track the speakers throughout game. Thus we do not have an analysis at the individual level, only at the group level.

"Dividing communication transcripts into units is a necessary first step in analyzing them by content analysis methods. Furthermore, the reliability of content-analysis studies depends not only on reliable rules for categorizing units but also on reliable rules for designating these units" (Auld and White 1956, p.1). The ensemble of communication transcripts from each experimental group constituted our context units; within each context unit, the pieces of text referring to each of the discussions in a round constituted our sampling units; and the statements within each sampling unit constituted our coding units $^{2}$. A statement (sentence) contains a subject (explicitly or implicitly stated) and a predicate (a verb with or without complements or adverbs). Although simpler structures can also express statements (e.g., everything is fine), sentences are the most common structures used for that purpose and particularly amenable for systematic coding (Auld and White 1956. Not all sentences within a communication interaction may constitute valid units for coding. To identify valid sentences within the sampling units we followed Auld and White's (1956) criteria ${ }^{3}$.

\subsubsection{Coding}

The coding process included two stages. In the first stage we tested the reliability of Auld and White's (1956) unitizing strategy, and assessed the applicability of Pavitt et al.'s (2005) coding scheme. We randomly selected transcripts from three groups and both authors coded them together. Both the unitizing and coding processes involved continuous

\footnotetext{
${ }^{2}$ Krippendorff (2004:101) distinguishes between context, sampling, and coding units. Context units are "the units of textual matter that set limits on the information to be considered in the description of recording units." Sampling units constitute the units of analysis that are to be compared in terms of coded units. Coding units are the ultimate expressions that are identified in the sampling units and coded into categories.

${ }^{3}$ Auld and White (1956) add to basic syntax rules some considerations about semantics. They take into consideration that statements are interrupted, recommenced, shortened, or repeated along a conversation to discriminate between statements that have with a self-standing meaning and thus are worthy of coding vs. other statements and expressions. We found their criteria very useful for the study. Additionally, we paid attention to semantics to refine syntax rules about dependent versus independent statements as we understood that some dependent statements can be separated as self-standing units of meaning. The ultimate unitizing scheme used in this study is available upon request to the authors.
} 
exchange of opinions and interpretations, which helped us refine the unitizing and coding schemes. In the process, we adapted Pavitt et al.'s (2005) coding scheme. First, we created a "field context" topic category to capture the potentially distinctive communication topic of discussions in field experiments and test the last hypothesis of this study. The category included statements about the natural resource use and management context of participants. Second, we did not include Pavitt et al 's (2005) topic categories of computation, elaboration, and confirmation or the procedural function category due to lack of data and concerns raised about their relevance. Alternatively, we created new subcategories of topic, including "collective action" vs. "free rider," "wrong interpretation," and "group results" vs. "individual results" to accommodate data that did not fit in Pavitt et al.'s (2005) scheme (see Tables 1.a and 1.b). Once the transcripts were coded, we entered the data into a content analysis software (N-Vivo 8.0) and ran queries of each category to revise the consistency of all the text quotations within each category.

\section{Table 1.a: Topic categories in coding book}

Category Name

\section{Game dynamics}

1.1 Collective action $^{\mathrm{a}}$

1.2 Free ridinga

1.3 Wrong interpretation ${ }^{\mathrm{a}}$

\section{Past results and actions}

2.1 Group past results ${ }^{a}$

2.2 Individual past results ${ }^{\mathrm{a}}$

\section{Collective strategy}

3.1 General collective strategy

3.2 Specific collective strategy

\section{Individualistic strategy}

\section{Description}

Statements describing the dilemma between individual appropriation and group gains

Statements describing the situation in which an individual can earn high rents at the expense of the cooperative behavior of other individuals

Statements pointing to game dynamics that do not correspond to the workings of the experimental game

Statements about what the group or individuals other than the speaker did in past rounds of the experiment

Statements about what the speaker did in past rounds of the experiment

Statements pointing to a general group strategy to be used in subsequent rounds of the experiment

Statements pointing to a specific group strategy (i.e. including specific numbers) to be used in subsequent rounds of the experiment

Statements pointing to strategies wherein each participant decides what to do independently from other participants' decisions 
Category Name Description

5. Field context

Statements pointing to the connections between the game and a common background of real-life situations (this includes references to both real people or natural resources)

6. Game rules

Statements about the rules that specify how decisions and computations are to be made in the experimental game

7. Off topic

Statements that do not fit in any of the preceding categories

a Sub-category added to original scheme

Source: Coding created by authors based on Pavitt et al. (2005).

Table 1.b: Function categories in coding book

\begin{tabular}{lll}
\hline Category Name & Description \\
\hline 1. Information & $\begin{array}{l}\text { Statements providing descriptions or non-normative opinions, as well as } \\
\text { potential acknowledgments following those statements }\end{array}$ \\
2. Proposal & $\begin{array}{l}\text { Statements suggesting a strategy to be followed in the subsequent rounds of } \\
\text { the experiment } \\
\text { Statements providing judgments and normative opinions, as well as } \\
\text { acknowledgments following those statements }\end{array}$ \\
3. Evaluation & $\begin{array}{l}\text { Statements showing appreciation, interest, affiliation, or social support for } \\
\text { the opinions and/or actions of other group members }\end{array}$ \\
5. Positive maintenance & $\begin{array}{l}\text { Statements of disapproval or criticism of the group or other players, as well } \\
\text { as expressions of nonconformity, disinterest, displeasure, or frustration with } \\
\text { the opinions and/or behaviors of other players. This category is similar to } \\
\text { the "evaluation" category because it involves judgment; additionally this } \\
\text { category includes a "reproaching" component that is not present in the } \\
\text { "evaluation" category. }\end{array}$
\end{tabular}

6. Off function

Statements that do not fit in any of the preceding categories

Source: Coding created by authors based on Pavitt et al. (2005)

${ }^{b}$ All statements are informative per se; however, some statements go beyond and use that information with a purpose other than just providing information. The information function refers to statements that are purely informative and do not involve any other functions.

In the second stage of the coding process, each author individually unitized and coded onehalf of the transcripts. Additionally, at the end of the coding process, to check for intercoder reliability, both authors coded the communication transcripts of three randomly selected groups. Then, we conducted a Guetzkow's (1950) U test and a Kappa coefficient test (Sim and Wright 2005) to compare the unitizing and coding results, respectively. The overall reliability of both the unitizing and the coding across the three groups ranged from fair to very high (see Annex 2 for a more detailed explanation). 
In sum, each hypothesis requires observing different topic categories, function categories, and interactions between topic and function categories, and their correlation with group extraction levels. To test Hypothesis 1 we observed Positive maintenance statements. Theory is not very informative about the kind of themes (Bornstein and Rapoport 1988; Bornstein et al. 1989; Orbell et al. 1988; Pavitt 2011; Sally 2001; Simon and Gorgura 2003) that would be prone to the effect of Positive maintenance on cooperation so we used the whole set of those statements without discriminating between topics covered. To test Hypothesis 2 we observed statements that (1) fulfilled an Information function and (2) uncovered topics that had been associated to the provision of information, i.e., Collective action, Past results and actions of others, and Past results and actions of oneself (Bochet and Putterman, 2009; Dawes et al., 1977; Bouas and Komorita, 1996; Chen and Komorita, 1994). By the same token, to test Hypothesis 3 we looked at statements with a Negative maintenance function that covered Past results and actions of others, and Past results and actions of oneself (Bicchieri 2002; Kerr and Kaufman-Gilliland 1994). Finally we tested hypothesis 4 by observing Field Context statements, i.e., uncovering connections between the experiment and a common background among the players. Just like with Hypothesis 1, theory is not very informative about the function that would make such statements particularly effective (or effective at all) in promoting cooperation so we observed the set of those statements as a whole.

Table 1.c presents a summary of all categories used to test the hypotheses, including intersections created between topic and function categories. Annex 3 shows examples of type of statements mentioned by participants for each one of the hypotheses.

Table 1.c: Categories used to test hypotheses

\begin{tabular}{|c|c|c|c|c|}
\hline \multirow[t]{2}{*}{ Hypothesis } & \multicolumn{2}{|l|}{ Interacting categories } & \multirow[t]{2}{*}{ Variable } & \multirow{2}{*}{$\begin{array}{l}\text { Group } \\
\text { extraction }\end{array}$} \\
\hline & Topic & Function & & \\
\hline H1 & & Positive maintenance & positive & Л \\
\hline \multirow[t]{3}{*}{$\mathrm{H} 2$} & Collective action & Information & collinfo & \multirow{3}{*}{$\sqrt{2}$} \\
\hline & Past results and actions of others & Information & pastothersinfo & \\
\hline & Past results and actions of oneself & Information & pastowninfo & \\
\hline
\end{tabular}




\begin{tabular}{|l|l|l|l|c|}
\hline \multirow{2}{*}{ H3 } & Past results and actions of others & Negative maintenance & pastothersnegative & $\sqrt{ }$ \\
\cline { 2 - 5 } & Past results and actions of oneself & Negative maintenance & pastownegative & $\sqrt{ }$ \\
\hline H4 & Field context & & & $\sqrt{ }$ 亿 \\
\hline
\end{tabular}

\section{Results}

We started the analysis by comparing group extraction differences before and after communication for each group. Table 2 shows that extraction levels decreased notably when communication was permitted in all but two groups (the differences between the rounds with no communication and the rounds with communication were not statistically significant). The decrease was statistically significant in 8 of the remaining 13 groups. This result is quite interesting because previous scholarship in laboratory economic experiments has shown that communication would generally increase cooperation among participants; however, as also noted in other studies on field experiments, the effects of communication can vary from one group to another (Ghate et al. 2013).

Table 2: Group mean extraction levels before and during communication rounds

\begin{tabular}{|c|c|c|c|}
\hline \multirow[b]{2}{*}{ Group } & \multicolumn{3}{|c|}{ Group mean extraction level } \\
\hline & $\begin{array}{l}\text { In rounds } \\
\text { communication }\end{array}$ & $\begin{array}{c}\text { before In rounds } \\
\text { communication }\end{array}$ & t test \\
\hline 1 & $36.1(8.3)$ & $33.3(3.3)$ & 0.5156 \\
\hline 2 & $29.3(5.0)$ & $23.1(5.5)$ & 0.0016 \\
\hline 3 & $31.4(6.5)$ & $28.7(3)$ & 0.3242 \\
\hline 4 & $38.5(5.2)$ & $28.5(5.9)$ & 0.0001 \\
\hline 5 & $38.1(6.6)$ & $39.4(5.4)$ & 0.7771 \\
\hline 6 & $37.7(7.4)$ & $31.1(9.6)$ & 0.1011 \\
\hline 7 & $37.1(9.7)$ & $22.5(5.1)$ & 0.0155 \\
\hline 8 & $38.8(6.2)$ & $31.6(9.9)$ & 0.0035 \\
\hline 9 & $30.1(6.1)$ & $34.8(9.9)$ & 0.2142 \\
\hline 10 & $38.8(9.9)$ & $30.3(5.1)$ & 0.0628 \\
\hline 11 & 35 (5.6) & 29.5 (7.1) & 0.0245 \\
\hline
\end{tabular}




\begin{tabular}{|c|c|c|c|}
\hline \multirow[b]{2}{*}{ Group } & \multicolumn{2}{|c|}{ Group mean extraction level } & \multirow[b]{2}{*}{ t test } \\
\hline & $\begin{array}{l}\text { In rounds } \\
\text { communication }\end{array}$ & $\begin{array}{l}\text { before In rounds } \\
\text { communication }\end{array}$ & \\
\hline 12 & $40.6(3.3)$ & $20.1(6.2)$ & 0.0000 \\
\hline 13 & $26.9(7)$ & $25.8(5)$ & 0.6062 \\
\hline 14 & $28.1(8.4)$ & $8.8(4.8)$ & 0.0004 \\
\hline 15 & $26.5(4.8)$ & $21.4(15.3)$ & 0.5594 \\
\hline
\end{tabular}

Note: Standard deviation in parenthesis. Paired t test presented.

Table 3 presents the intersection of the two coding categories, to wit, the frequencies of the topic and function categories. In the topic category, most of the statements were Off Topic, followed by statements about Group Past Results and Individual Past Results, whereas in the topic category, most of the statements were about Information, Proposal, and Evaluation. Most of the statements on Field Context were Information and Proposal categories. The intersections between Information and Individual Past Results, Information and Group Past Results, Proposal and Specific Collective Strategy, and Information and Collective Action are the intersections categories where we found most of the statements. Other intersections that seem to be prominent are Negative Maintenance and Group Past Results, Evaluation and Individual Past Result, Proposal and General Strategy, Evaluation and Group Past Results. Finally, 359 out of 1,493 statements coded were classified as Off Topic. The fact that participants discuss functions that may not seem relevant for the game may be a characteristic of experiments in the field. 
This is an Accepted Manuscript of the article Lopez, M. C., \& Villamayor-Tomas, S. (2017). Understanding the black box of communication in a commonpool resource field experiment. Environmental Science \& Policy, 68, 69-79, available online at: https://doi.org/10.1016/j.envsci.2016.12.002

(C)2017. This manuscript version is made available under the CC-BY-NC-ND 4.0 license.

Table 3: Intersection of frequencies of topic and function categories in all groups and rounds

\begin{tabular}{|c|c|c|c|c|c|c|c|}
\hline Topic Function & 1. Information & 2. Proposal & 3. Evaluation & $\begin{array}{l}\text { Positive } \\
\text { maintenance }\end{array}$ & $\begin{array}{l}\text { 5. Negative } \\
\text { maintenance }\end{array}$ & $\begin{array}{l}\text { 6. Off } \\
\text { function }\end{array}$ & Total \\
\hline 1.1 Collective action & 101 & 0 & 10 & 3 & 0 & 1 & 115 \\
\hline 1.2 Free ride & 9 & 0 & 1 & 1 & 3 & 0 & 14 \\
\hline 1.3 Wrong interpretation & 43 & 1 & 3 & 0 & 1 & 0 & 48 \\
\hline 2.1 Group past results & 114 & 0 & 69 & 12 & 93 & 0 & 288 \\
\hline 2.2 Individual past results & 121 & 0 & 81 & 0 & 16 & 0 & 218 \\
\hline 3.1 General C. strategy & 11 & 79 & 3 & 25 & 4 & 0 & 122 \\
\hline 3.2 Specific C. strategy & 18 & 112 & 9 & 27 & 3 & 0 & 169 \\
\hline 4. Individualistic strategy & 7 & 13 & 0 & 2 & 8 & 1 & 31 \\
\hline 5. Field context & 45 & 28 & 6 & 6 & 13 & 2 & 100 \\
\hline 6. Game rules & 8 & 0 & 1 & 1 & 3 & 2 & 15 \\
\hline 7. Off topic & 190 & 7 & 42 & 12 & 20 & 88 & 359 \\
\hline Total & 669 & 240 & 228 & 89 & 173 & 94 & 1,493 \\
\hline
\end{tabular}


Table 4 shows correlation coefficients between the average group extraction levels in all rounds where communication was allowed and the different coding categories. The topic categories having a negative and significant relationship with group extraction levels are Collective Action (i.e. statements describing the dilemma between individual appropriation and group gains), Group Past Results (i.e. statements about what the group did in past rounds), Specific Collective Strategy (i.e. statements about the specific strategies that players should follow in subsequent rounds).

The negative correlation between statements about past results and actions and extraction levels should be taken with caution, since it is only when the statements address the group's past results and not the speaker's results that communication has a significant relationship with group extraction level. Similarly, the relationship between statements about collective strategies and group extraction levels should be assessed carefully since it is only when those statements address specific strategies (i.e. saying "we should extract 1 or 2" rather than "we should extract less") that communication has a significant relationship with group extraction levels.

Among the function categories, only Negative Maintenance (i.e. statements of disapproval or criticism) has a negative and significant effect on group extractions. Through disapproval, participants would be reinforcing the correct action, i.e. extracting fewer units from the CPR. In some sense these negative maintenance statements are calls for the group or individuals to change the way they are behaving. The rest of the table gives some statistical support to the information already presented in Table 3.

The results just presented would fail to support arguments about the positive role of group membership (our Hypothesis 1) to enhance cooperation, and the fact that the field context may be influencing the results if the game (our Hypothesis 4). These results would tend to 
support that information sharing and reproaching have a positive impact in people's cooperative behaviors (our Hypotheses 2 and 3). 
This is an Accepted Manuscript of the article Lopez, M. C., \& Villamayor-Tomas, S. (2017). Understanding the black box of communication in a commonpool resource field experiment. Environmental Science \& Policy, 68, 69-79, available online at: https://doi.org/10.1016/j.envsci.2016.12.002

(C)2017. This manuscript version is made available under the CC-BY-NC-ND 4.0 license.

Table 4: Correlation coefficients between average group extraction level and coding categories

\begin{tabular}{|c|c|c|c|c|c|c|}
\hline Category & $\begin{array}{l}\text { Group } \\
\text { extraction }\end{array}$ & 1. Information & 2. Proposal & 3. Evaluation & $\begin{array}{l}\text { 4. Positive } 5 . \\
\text { maintenance }\end{array}$ & $\begin{array}{l}\text { Negative } \\
\text { maintenance }\end{array}$ \\
\hline 1.1 Collective action & $-0.20^{* *}$ & $0.49^{* * *}$ & $0.59 * * *$ & $0.28^{* * *}$ & $0.20^{* *}$ & -0.01 \\
\hline 1.2 Free riding & 0.09 & -0.01 & $0.25^{* * *}$ & $0.17^{*}$ & $0.16^{*}$ & 0.05 \\
\hline 1.3 Wrong interpretation & -0.03 & $0.45^{* * *}$ & $0.35^{* * *}$ & 0.11 & 0.16 & -0.14 \\
\hline 2.1 Group past results & $-0.19^{* *}$ & 0.20 & 0.02 & 0.14 & 0.11 & $0.70^{* * *}$ \\
\hline 2.2 Individual past results & -0.03 & $0.29 * * *$ & $0.18^{* *}$ & $0.30^{* * *}$ & $0.24^{* *}$ & $0.37^{* * *}$ \\
\hline 3.1 General collective strategy & -0.02 & $0.34^{* * *}$ & $0.71^{* * *}$ & $0.28^{* * *}$ & $0.52^{* * *}$ & 0 \\
\hline 3.2 Specific collective strategy & $-0.21^{* *}$ & $0.22^{* *}$ & $0.88^{* * *}$ & 0.14 & $0.44^{* * *}$ & 0.08 \\
\hline 4. Individualistic strategy & -0.13 & -0.02 & $0.22^{* *}$ & -0.04 & $0.18^{*}$ & $0.29 * * *$ \\
\hline 5.Field context & 0.12 & $0.36^{* * *}$ & 0.13 & 0.13 & 0 & 0.01 \\
\hline 6. Games rules & -0.09 & 0.12 & 0.12 & 0.04 & 0.28 & 0.09 \\
\hline 1. Information & 0.03 & & & & & \\
\hline 2. Proposal & -0.12 & & & & & \\
\hline 3. Evaluation & 0.12 & & & & & \\
\hline 4. Positive maintenance & -0.07 & & & & & \\
\hline 5. Negative maintenance & $-0.26^{* * *}$ & & & & & \\
\hline
\end{tabular}

Significance levels: ${ }^{* * *}=0.0 ;{ }^{* *}=0.05 ;^{*}=0.1$

Note: Off Topic and Off Function categories have been excluded due to lack of meaningful interpretation. 
To further analyze our data, we developed a series of three OLS models. The dependent variable in all models is group extraction level, and the unit of analysis in all models is the decision round. The regressions include only the rounds with communication, but in all models we control for the average extraction level of that particular group in the rounds where communication was not permitted. Additionally, in all models we include the variable round to account for the fact that the decision setting had different rounds and potential learning effects.

In the first model, presented in Table 5, we include a selection of topic categories that are relevant to test our hypotheses (see Table 1.c). The model confirms some of the findings of the correlation analysis. The Collective Action variable has a negative effect on group extraction levels (10\% significance level), meaning that groups discussing the dilemma between individual and collective extraction extract fewer units and thus cooperate more in the experiment. The Field Context variable does not have an effect on extraction levels, which fails to support Hypothesis 4. Also, the impact of the Specific Collective Strategy variable is significant and negative (5\% significance level) whereas the effect of the General Collective Strategy variable is significant and positive (10\% significance level). According to this, the level of specificity in collective strategies makes a big difference in the levels of cooperation, with general strategies causing more harm than good and specific statements improving cooperation. Finally, the statements about Group Past Results notably decrease group extraction levels (5\% significance level), while statements on Individual Past Results have no effect on cooperation. One possible interpretation of this last result is that discussing how the group performed in past rounds may be more efficient and relevant for the group in terms of information sharing than letting each participant share his/her actions and results but not connecting them to the results of the group. 
Table 5: OLS Coefficients for topic categories

\begin{tabular}{lcc}
\hline & \multicolumn{2}{c}{ Group extractions } \\
\cline { 2 - 3 } Variable & Coefficient & Standard error \\
\hline Constant (group extraction) & $31.16^{* * *}$ & 5.83 \\
Collective action & $-1.03^{*}$ & 0.53 \\
Field context & 0.41 & 0.33 \\
General collective strategy & $0.88^{*}$ & 0.48 \\
Specific collective strategy & $-0.65^{* *}$ & 0.30 \\
Group past results & $-0.80^{* *}$ & 0.32 \\
Individual past results & 0.64 & 0.45 \\
Round & -0.12 & 0.36 \\
Mean rounds first set of rounds $(\mathrm{no}$ & 0.30 & 0.21 \\
communication) & & \\
Adj. $\mathrm{R}^{2}=0.158$ & & \\
\hline Significance levels: & \\
& &
\end{tabular}

In a second OLS model, found in Table 6, we regressed group extractions on the function categories. Almost none of the variables had a significant impact on group extraction levels. The impact of the Information and Proposal variables were not significant, meaning that the exchange of any piece information does not necessarily explain extraction levels. Positive Maintenance statements had no effect on group extraction levels either (i.e. statements showing appreciation or interest for other group members' opinions or actions did not enhance cooperation). This result fails to support our first hypothesis, which posited a positive relationship between positive maintenance statements and cooperation. Only the Negative Maintenance category (i.e. statements of disapproval or criticism for the group or other players) had a significant, and negative, effect on extraction levels (5\% significance level). This latter result supports Hypothesis 3.

Table 6: OLS coefficients for function categories

\begin{tabular}{lll}
\hline & \multicolumn{2}{c}{ Group extractions } \\
\cline { 2 - 3 } Variable & Coefficient & Standard error \\
\hline Constant (group extraction) & 15.08 & 9.11 \\
Information & 0.07 & 0.20 \\
Proposal & -0.28 & 0.27 \\
Evaluation & 0.57 & 0.50 \\
\hline
\end{tabular}




\begin{tabular}{lll}
\hline & \multicolumn{2}{l}{ Group extractions } \\
\cline { 2 - 3 } Variable & Coefficient & Standard error \\
\hline Positive maintenance & 0.03 & 0.79 \\
Negative maintenance & $-0.68^{* *}$ & 0.27 \\
Round & 0.23 & 0.40 \\
Mean rounds first set of rounds (no 0.27 & 0.27 \\
communication) & & \\
Adj. $\mathrm{R}^{2}=0.118$ & & \\
\hline Note: Significance levels: & $* * *=0.01 ; * *=0.05 ; *=0.1$
\end{tabular}

In our last model, presented in Table 7, we include different interactions between topic and function categories as a more accurate test of our hypotheses. The model encompasses all relevant variables to test the hypotheses (see Table 1.c) ${ }^{4}$.

Table 7: OLS Coefficients for topic-function categories

\begin{tabular}{lcc}
\hline & Group extractions \\
\cline { 2 - 3 } Variable & Coefficient & $\begin{array}{l}\text { Standard } \\
\text { error }\end{array}$ \\
\hline Constant (group extraction) & $15.80^{*}$ & 8.82 \\
Positive maintenance & 0.18 & 0.74 \\
Colectinfo & $-1.08^{* *}$ & 0.483 \\
Pastotherinfo & 0.324 & 0.623 \\
Pastowninfo & -0.557 & 0.58 \\
Psothersnegative & $-1.22^{*}$ & 0.63 \\
Psownnegative & 0.76 & 2.39 \\
Fieldinfo & $1.13^{*}$ & 0.60 \\
Fieldpositive & $-3.32^{*}$ & 1.73 \\
Round & -0.01 & 0.37 \\
Mean rounds first set of rounds (no communication) & $0.406^{*}$ & 0.206 \\
Adj. $\mathrm{R}^{2}=0.12$ & & \\
\hline
\end{tabular}

Significance levels: ${ }^{* * *}=0.01 ;^{* *}=0.05 ;^{*}=0.1$

Note: The asterisks in the variables below denote the intersection between these two variables.

Colectinfo $=$ Collective Action $*$ Information; Pastothersinfo, $=$ Group Past Results ${ }^{*}$ Information; Pastowninfo= Individual Past Results * Information; Psothersnegative $=$ Group Past Results * Negative Maintenance; Psownnegative $=$ Individual Past Results $*$ Negative Maintenance; Fieldinfo $=$ Field Context* Information; Fieldpositive $=$ Field Context ${ }^{*}$ Positive Maintenance

\footnotetext{
${ }^{4}$ After a first trial including the Field Context variable alone (which had a positive but not significant effect), we carried a step-wise exploration of the effect of interactions between Field Context and Positive maintenance and Field Context and Information.
} 
As shown in Table 7, the coefficient for Positive Maintenance is not statistically significant, meaning that statements affirming group membership alone do not have an impact on group extraction. Once again, these results do not support Hypothesis 1.

We find that the coefficient of Colectinfo (interaction of Collective Action* Information statements) is negative and significant at 5\% meaning that statements that help participants understand the social dilemma of the game result in an increase of cooperation. This result supports Hypothesis 2 and the argument about the contribution of communication to cooperation through information sharing. Alternatively, neither Pastotherinfo (Group Past Results * Information) nor Pastowninfo (Individual Past Results * Information) have a significant effect on group extraction levels, which fails to support the same hypothesis. These results help to further refine our previous observation about the lack of impact of any piece of information on cooperation. Sharing information about the behavior and payoffs of the players in a social dilemma does not have any effect on cooperation, but the provision of information about the dynamics of the game and the collective-action dilemma that it entails does.

The coefficient of Psothersnegative (Group Past Results * Negative Maintenance) is negative and significant at 5\%, but the effect of Psownnegative (Individual Past Results * Negative Maintenance) is not significant. This result qualifies our previous findings about Hypothesis 3 and the argument about the contribution of communication to cooperation through social norms. The negative impact of Psothersnegative and the lack of impact of the Pastotherinfo suggest that the effect of statements about results and actions performed by the group depends on the reproach vs. information function of those statements, where the first one has an impact on cooperation and the latter does not.

The Fieldinfo (Field Context ${ }^{*}$ Information) variable is positive and statistically significant at $10 \%$ level, indicating that when individuals bring their own experiences from real life into the experiment in an informative way, group extractions increase. Alternatively, the Fieldpositive (Field Context * Positive Maintenance) variable is negative and statistically 
significant at $10 \%$. The number of observations behind this variable is quite low (6), so the result has to be taken with caution. Overall, these findings supports our Hypothesis 4, suggesting that when statements about the context are used to show appreciation, interest, affiliation, or social support for other group members, cooperation increases. More importantly, the impact of a common background among individuals sharing a social dilemma can have a positive as well as negative impact on cooperation levels depending on the intention of those who mobilize that common background (e.g. to increase social cohesion vs. inform, or maybe other functions), and also the experiences the users have sharing their resources.

\section{Discussion}

According to our analysis, we did not find an impact coming from positive maintenance statements as a whole (hypothesis 1); however, we found a positive impact from the subset of statements that refer to positive maintenance and the field context of participants (Fieldpositive). These results qualify previous works about the positive effect of group identity and sympathy on cooperation (Bornstein et al. 1989; Orbell et al. 1988; Sally 2001) and suggest that such an effect may be facilitated when participants can mobilize shared experiences. More broadly, the results qualify previous findings about the positive impact of material rewards vs. punishments in experimental contexts (Rand et al. 2009). Further research will explore the extent to which verbal punishments and rewards compare to each other.

Results about the impact of information sharing are mixed (hypothesis 2). Although informative statements about the collective-action dilemma can enhance cooperation, informative statements about what the group or individuals did in past rounds have no impact on cooperation. This result suggests that exchanging information to reach a common understanding of a situation may have very different implications in terms of collective action than exchanging information just for the sake of updating individuals' strategic behaviors. Recognizing the difference between the two processes can actually help understand contradictory findings in previous studies about the impact of information 
on cooperation (see particularly Bouas and Komorita 1996; Chen and Komorita 1994; Kerr and Kaufman-Gilliland 1994; Pavitt 2011). Confirming whether that distinction and the more general discrimination between different types of information make a difference in terms of cooperation in social dilemmas justifies further research.

Also, importantly, the impact of statements about past results and actions can change depending on the information vs. reproach function of those statements. This finding constitutes an important piece of evidence supporting the social norms argument against the information argument. More broadly, the result illustrates the importance of distinguishing between topic and function of statements (Pavitt et al. 2005) and the interest of further exploring their interactions to better understand how communication can contribute to cooperation.

When participants talk about their individual past decisions and payoffs, cooperation does not change; however, when participants focus on the decisions and payoffs of other individuals or the group as a whole, cooperation tends to increase. This finding can be interpreted with regard to communication efficiency. Discussing how the group performed in past rounds may be more efficient in terms of information sharing than letting each participant share his/her actions and results one at a time. Further research might explore the role of efficiency in communication and its impact on cooperation.

We found that statements on specific strategies can increase cooperation and statements on strategies that are not specific enough can actually decrease cooperation. This result qualifies Bochet and Putterman's (2009) finding about the positive effects of pre-play announcements, and aligns with Chen and Komorita's (1994) finding on the positive effect of minimum-binding pledges vs. non-binding messages. Additionally, the finding suggests that the line separating the positive from the negative impact of communication on cooperation is a fine one and that previously unstudied qualities of communication such as the level of specificity can make a difference. 
The results clearly support the social norms argument (Bicchieri 2002; Kerr and KauffmanGilliland 1994; Kerr et al. 1997) over the group identity and information argument (Bouas and Komorita 1996; Brosig et al. 2003; Chen and Komorita 1994; Dawes et al. 1977). The impact of negative maintenance statements (i.e. statements of disapproval or criticism of the group or other players) is robust across all the models we developed (hypothesis 3 ). This result becomes particularly evident when negative maintenance statements refer to the past behavior and payoffs of the group.

According to our analysis, the field context permeates the communication process in many ways, with subsequent consequences in the game (hypothesis 4). We found that statements about the field context can have a positive impact on cooperation if those statements aim to enhance group cohesion. But if statements are only informative then cooperation decreases. This result extends the findings in Ghate et al. (2013) and Cardenas (2003) suggesting that the effectiveness of communication in the field depends not only on the common background participants bring to the game but also the way participants report about those experiences (i.e, the function of their communication statements). Overall, our findings regarding the field context show the need to do more research on this communicative aspect. Field experiments are a promising way to do so, when they are combined with a content analysis of the communication processes.

The function categories were not as explanatory as we had anticipated. This may mean that for field experiments we need to tailor the function categories to the specific ways affairs discussed by participants in field settings.

There are several limitations of this study that need to be mentioned. First, there are some limitations in the quality of the data. When the experiments were conducted, the researcher was not aiming to explore the content of discussions; therefore, the transcriptions of the discussions did not allow for identifying each person speaking and prevented the study of discussions at the individual level and/or the emergence and role of discussion leaders. In the same line of statements, we know that many of the participants intervened in the discussions, but we cannot say how many of them and/or how frequently 
they did. However, methodologically, this study shows that a systematic content analysis can be a step further in the use of experiments to better understand why communication can contribute to cooperation. Improved coding schemes and collection of communication data, particularly in field experiments, will facilitate synergies between content analysis and experimental methods. More reliable coding schemes and communication data might in turn encourage experimentalists to take into account the possibility of studying not only the outcomes of participants' decisions but also the rationale and dynamics behind some of those decisions when participants have the opportunity to communicate.

\section{Conclusions}

We wanted to understand the mechanisms by which communication has an impact on cooperation, with a particular focus on the role of field context. For that purpose, we content-analyzed data from field experiments and did a series of OLS models explaining cooperation.

Three main theoretical conclusions can be extracted from the analysis. First, our results show evidence supporting the social norms argument over the information and group identity arguments about the relationship between communication and cooperation. Statements promoting group cohesiveness had no effect on cooperation except when referring to the common context and/or experiences of participants. Similarly, the impact of information statements depended on whether those statements addressed the social dilemma (improvement of cooperation) or focused on past results and actions of the participants (no effect). On the contrary, statements of disapproval, specifically when centered on the group's past results and actions, consistently improved cooperation across all the analyses.

The second theoretical conclusion relates to the role of communication in field experiments. As pointed out by other scholars, participants can bring different experiences from their own context into experiments, with different results depending on the positive 
or negative nature of those experiences (Cárdenas and Ostrom 2004; Ostrom 2006; Poteete et al. 2010). According to our results, the impact of previous experiences and context on cooperation can be channeled via communication and in that way may also depend on the intention (i.e. function) of communication interactions. Studying the communication process in the field is a promising area of study since our results indicate that statements related to the field can increase or decrease cooperation. This result clearly shows the complexity of field experiments. 


\section{References}

Agrawal, A. (2001). Common property institutions and sustainable governance of resources. World Development, 29(10), 1649-1672.

Agrawal, A. (2014). Studying the commons, governing common-pool resource outcomes: Some concluding thoughts. Environmental Science \& Policy, 36, 86-91.

Andersson, K. P. (2004). Who talks with whom? The role of repeated interactions in decentralized forest governance. World Development, 32(2), 233-249.

Auld, F., \& White, A. M. (1956). Rules for dividing interviews into statements. The Journal of Psychology, 42(2), 273-281. doi:10.1080/00223980.1956.9713040

Baland, J.-M., \& Platteau, J.-P. (1996). Halting Degradation of Natural Resources: Is There a Role for Rural Communities? Rome: Food and Agriculture Organization of the United Nations.

Balliet, D. (2010). Communication and cooperation in social dilemmas: a meta-analytic review. Journal of Conflict Resolution, 54(1), 39-57. doi:10.1177/0022002709352443

Bicchieri, C. (2002). Covenants without swords: group identity, norms, and communication in social dilemmas. Rationality and Society, 14(2), 192-228. doi: $10.1177 / 1043463102014002003$

Bochet, O., \& Putterman, L. (2009). Not just babble: opening the black box of communication in a voluntary contribution experiment. European Economic Review, 53(3), 309-326. doi:10.1016/j.euroecorev.2008.09.005

Bornstein, G. (1992). Group decision and individual choice in intergroup competition for public goods. In D. Leibrand, D. Messick, \& H. Wilke (Eds.), Social Dilemmas: Theoretical Issues and Research Findings (pp. 247-263). Oxford, UK: Pergamon Press.

Bornstein, G., \& Rapoport, A. (1988). Intergroup competition for the provision of step-level public goods: Effects of preplay communication. European Journal of Social Psychology, 18(2), 125-142. doi:10.1002/ejsp.2420180205

Bornstein, G., Rapoport, A., Kerpel, L., \& Katz, T. (1989). Within- and between-group communication in intergroup competition for public goods. Journal of Experimental Social Psychology, 25(5), 422-436. doi:10.1016/0022-1031(89)90031-0 
Bouas, K., \& Komorita, S. S. (1996). Group discussion and cooperation in social dilemmas. Personality and Social Psychology Bulletin, 22(11), 1144-1150. doi:10.1177/01461672962211005

Brosig, J., Weimann, J., \& Ockenfels, A. (2003). The effect of communication media on cooperation. German Economic Review, 4(2), 217-241. doi:10.1111/1468-0475.00080

Cardenas, J.-C. (2000). Rural institutions, poverty and cooperation: learning from experiments and conjoint analysis in the field. Doctoral dissertation. University of $\begin{array}{llll}\text { Massachusetts } & \text { Amherst. } & \text { Retrieved }\end{array}$ http://scholarworks.umass.edu/dissertations/AAI9978482/

Cardenas, J.-C. (2003). Real wealth and experimental cooperation: experiments in the field lab. Journal of Development Economics, 70(2), 263-289. doi:10.1016/S03043878(02)00098-6

Cardenas, J. C. (2011). Social norms and behavior in the local commons as seen through the lens of field experiments. Environmental and Resource Economics, 48(3), 451-485.

Cardenas, J.-C., \& Ostrom, E. (2004). What do people bring into the game? Experiments in the field about cooperation in the commons. Agricultural Systems, 82(3), 307-326. doi:10.1016/j.agsy.2004.07.008

Chen, X., \& Komorita, S. S. (1994). The effects of communication and commitment in a public goods social dilemma. Organizational Behavior and Human Decision Processes, 60(3), 367-386. doi:10.1006/obhd.1994.1090

Dawes, R. M., McTavish, J., \& Shaklee, H. (1977). Behavior, communication, and assumptions about other people's behavior in a commons dilemma situation. Journal of Personality and Social Psychology, 35(1), 1-11. doi:10.1037/0022-3514.35.1.1

Dietz, T., \& Henry, A. D. (2008). Context and the commons. Proceedings of the National Academy of Sciences of the United States of America, 105(36), 13189-13190.

Etzioni, A. (1996). The New Golden Rule: Community and Morality in a Democratic Society (1st ed.). New York: BasicBooks.

Gächter, S., \& Fehr, E. (1999). Collective $\{A\}$ ction as a $\{S\}$ ocial $\{$ E\}xchange. Journal of Economic Behavior \& Organization, 39(4), 341-369. doi:10.1016/S01672681(99)00045-1 
Gelcich, S., Guzman, R., Rodríguez-Sickert, C., Castilla, J. C., \& Cárdenas, J. C. (2013). Exploring external validity of common pool resource experiments: insights from artisanal benthic fisheries in Chile. Ecology and Society, 18(3), art2. doi:10.5751/ES05598-180302

Ghate, R., Ghate, S., \& Ostrom, E. (2013). Cultural norms, cooperation, and communication: taking experiments to the field in indigenous communities. International Journal of the Commons, 7(2), 498-520. doi:10.18352/ijc.376

Guetzkow, H. (1950). Unitizing and categorizing problems in coding quantitative data. Journal of Clinical Psychology, 6(1), 47-58.

Gurven, M., \& Winking, J. (2008). Collective action in action: prosocial behavior in and out of the laboratory. American Anthropologist, 110(2), 179-190. doi:10.1111/j.15481433.2008.00024.x

Harrison, G. W., \& List, J. A. (2004). Field experiments. Journal of Economic Literature, 42(4), 1009-1055. doi:10.1257/jep.6.3.79

Henrich, J., Heine, S. J., \& Norenzayan, A. (2010). Most people are not WEIRD. Nature, 466(7302), 29. doi:10.1017/S0140525X0999152X

Hill, K., \& Gurven, M. (2004). Economic experiments to examine fairness and cooperation among the Ache Indians of Paraguay. In J. Henrich, R. Boyd, S. Bowles, C. Camerer, E. Fehr, \& H. Gintis (Eds.), Foundations in Human Sociality: Economic Experiments and Ethnographic Evidence from Fifteen Small-Scale Societies (pp. 382-412). Oxford University Press.

Kerr, N. L., Garst, J., Lewandowski, D. A., \& Harris, S. E. (1997). That still, small voice: commitment to cooperate as an internalized versus a social norm. Personality and Social Psychology Bulletin, 23(12), 1300-1311. doi:10.1177/01461672972312007

Kerr, N. L., \& Kaufman-Gilliland, C. M. (1994). Communication , commitment, and cooperation in social dilemmas. Journal of Personality and Social Psychology, 66(3), 513-529. doi:10.1037/0022-3514.66.3.513

Krippendorff, K. (2004). Content analysis: An introduction to its methodology. Sage

List, J. A., \& Metcalfe, R. (2014). Field experiments in the developed world: an introduction. Oxford Review of Economic Policy, 30(4), 585-596. doi:10.1093/oxrep/grv005 
Lopez, M. C., Murphy, J. J., Spraggon, J. M., \& Stranlund, J. K. (2012). Comparing the effectiveness of regulation and pro-social emotions to enhance cooperation: experimental evidence from fishing communities in Colombia. Economic Inquiry, 50(1), 131-142. doi:10.1111/j.1465-7295.2010.00344.x

Masclet, D., Noussair, C. N., Tucker, S., \& Villeval, M.-C. (2003). Monetary and nonmonetary in the voluntary punishment monetary contributions mechanism. American Economic Review, 93(1), 366-380. doi:10.1257/000282803321455359

Orbell, J. M., van de Kragt, A. J. C., \& Dawes, R. M. (1988). Explaining discussion-induced cooperation. Journal of Personality and Social Psychology, 54(5), 811-819. doi:10.1037/0022-3514.54.5.811

Ostrom, E. (1990). Governing the Commons: The Evolution of Institutions for Collective Action. Cambridge University Press.

Ostrom, E. (2006). The value-added of laboratory experiments for the study of institutions and common-pool resources. Journal of Economic Behavior \& Organization, 61(2), 149163. doi:10.1016/j.jebo.2005.02.008

Ostrom, E. (2007). A diagnostic approach for going beyond panaceas. Proceedings of the National Academy of Sciences of the United States of America, 104(39), 15181-15187. doi:10.1073/pnas.0702288104

Ostrom, E., Gardner, R., \& Walker, J. (1994). Rules, Games and Common-Pool Resources. Ann Arbor: University of Michigan Press.

Ostrom, E., Janssen, M. A., \& Anderies, J. M. (2007). Going beyond panaceas. Proceedings of the National Academy of Sciences of the United States of America, 104(39), 1517615178. doi:10.1073/pnas.0701886104

Ostrom, E., \& Walker, J. (1991). Communication in a commons: cooperation without external enforcement. In T. R. Palfrey (Ed.), Laboratory Research in Political Economy. Ann Arbor: University of Michigan Press.

Ostrom, E., Walker, J., \& Gardner, R. (1992). Covenants with and without a sword: selfgovernance is possible. American Political Science Review, 86(02), 404-417. doi:10.2307/1964229 
Pavitt, C. (2011). Communication, performance, and perceptions in experimental simulations of resource dilemmas. Small Group Research, 42(3), 283-308. doi:10.1177/1046496411399782

Pavitt, C., Braddock, K., \& Mann, A. (2009). Group communication during resource dilemmas: 3. Effects of social value orientation. Communication Quarterly, 57(4), 433451. doi:10.1080/01463370903320856

Pavitt, C., High, A. C., Tressler, K. E., \& Winslow, J. K. (2007). Leadership communication during group resource dilemmas. Small Group Research, 38(4), 509-531. doi:10.1177/1046496407304333

Pavitt, C., McFeeters, C., Towey, E., \& Zingerman, V. (2005). Communication during resource dilemmas: 1. Effects of different replenishment rates. Communication Monographs, 72(3), 345-363. doi:10.1080/03637750500206482

Pavitt, C., Zingerman, V., Towey, E., \& McFeeters, C. (2006). Group communication during resource dilemmas. Communication Research, 33(1), 64-91. doi:10.1177/0093650205283102

Poteete, A. R., Janssen, M., \& Ostrom, E. (2010). Working Together: Collective Action, the Commons, and Multiple Methods in Practice. Princeton University Press.

Rand, D. G., Dreber, A., Ellingsen, T., Fudenberg, D., \& Nowak, M. A. (2009). Positive interactions promote public cooperation. Science, 325(5945), 1272-1275.

Rege, M., \& Telle, K. (2004). The impact of social approval and framing on cooperation in public good situations. Journal of Public Economics, 88(7-8), 1625-1644. doi:10.1016/S0047-2727(03)00021-5

Rustagi, D., Engel, S., \& Kosfeld, M. (2010). Conditional cooperation and costly monitoring explain success in forest commons management. Science, 330(6006), 961-965. doi:10.1126/science.1193649

Sally, D. (1995). Conversation and cooperation in social dilemmas: a meta-analysis of experiments from 1958 to 1992. Rationality and Society, 7(1), 58-92. doi:10.1177/1043463195007001004

Sally, D. (2001). On sympathy and games. Journal of Economic Behavior and Organization, 44(1), 1-30. doi:10.1016/S0167-2681(00)00153-0 
Schwartz-Shea, P., \& Simmons, R. T. (1991). Egoism, parochialism, and universalism. Rationality and Society, 3(1), 106-132. doi:10.1177/1043463191003001007

Shankar, A., \& Pavitt, C. (2002). Resource and public goods dilemmas: a new issue for communication research. Review of Communication, 2(July), 251-272.

Sim, J., \& Wright, C. C. (2005). The Kappa statistic in reliability studies: use, interpretation, and sample size requirements. Physical Therapy, 85(3), 257-268.

Simon , A. F. and H. E. Gorgura (2003). Say the Magic Word: Effective Communication in Social Dilemmas. Working Paper. New Haven, CT: Yale University.

Torres-Guevara, L. E., \& Schlüter, A. (2016). External validity of artefactual field experiments: A study on cooperation, impatience and sustainability in an artisanal fishery in Colombia. Ecological Economics, 128, 187-201.

Tucker, C. M. (2010). Learning on governance in forest ecosystems: lessons from recent research. International Journal of the Commons, 4(2), 687-706. doi: http://doi.org/10.18352/ijc.224.

Turner, J. C., Hogg, M. A., Oakes, P. J., Reicher, S. D., \& Wethrell, M. (1987). Rediscovering the Social Group: A Self-Categorization Theory. Cambridge, MA: Basil Blackwell.

Wade, R. (1988). The management of irrigation systems: how to evoke trust and avoid prisoners' dilemma. World Development, 16(4), 489-500. doi:10.1016/0305750X(88)90199-4. 